\title{
AGRICULTURA, COMÉRCIO E PROTEÇÃO \\ UMA SÍNTESE IMPOSSÍVEL? O CASO DAS INDICAÇÕES GEOGRÁFICAS ${ }^{1}$
}

\author{
AGRICULTURA, COMERCIO Y PROTECCIONISMO \\ UNA SÍNTESIS IMPOSIBLE? EL CASO DE LAS INDICACIONES \\ GEOGRÁFICAS
}

\begin{abstract}
AGRICULTURE, TRADE AND PROTECTIONISM
AN IMPOSSIBLE SYNTHESIS? THE CASE OF GEOGRAPHICAL INDICATIONS
\end{abstract}

\author{
Guido Sali, Chiara Mazzocchi \\ Dip. di Scienze Agrarie e Ambientali, Produzione, Territorio, Agroenergie - Unimi \\ guido.sali@unimi.it, chiara.mazzocchi1@unimi.it
}

Resumo: Nas últimas décadas a globalização do mercado agro-alimentar gerou a necessidade de poder diferenciar as produções também conferindo às empresas marcas de qualidade para os seus produtos. Neste sentido o sistema das Indicações Geográficas é um dos instrumentos mais adequados para garantir o reconhecimento da qualidade a nível internacional. O presente artigo apresenta uma reflexão sobre a funcionalidade das Indicações Geográficas como instrumento de mercado, e sobre as suas potencialidades de valorização dos produtos da cadeia agro-alimentar, expondo o caso do Feta grego e expressando algumas considerações sobre a teoria das IG como bens de mercado.

Palavras-Chave: OMC, mercado agrícola, acordos internacionais, indicações geográficas, bens de clube.

Resumen: En los últimos años la globalización del mercado de los alimentos ha hecho necesaria la diferenciación de la producción, por ejemplo utilizando etiquetas de calidad con el fin de render reconocibles productos de calidad. En este sentido, los sistemas de Indicaciones Geográficas son las herramientas que mejor aseguran la identificatión de la calidad a nivel internacional. Este paper presenta una reflexión sobre la funcionalidad de las Indicaciones Geográficas como herramienta por la regulación del mercado y por la valorización de los productos de la cadena alimentaria.

Palabras Claves: WTO, mercado agrícola, acuerdos internacionales, indicaciones geográficas, bienes de club.

\begin{abstract}
In recent years food market globalization has led to the need of differentiating productions, for instance by recognizing products quality thanks to quality labels. In this regard Geographical Indications' system is one of the tools most likely to ensure the recognition of the quality at an international level. This paper presents a reflection on the functionality of Geographical Indications as a tool for market regulation and for tha valorization of food chain products.
\end{abstract}

\footnotetext{
1 Pesquisa financiada pela Região Lombardia e Expo2015 s.p.a. no âmbito do projeto Dote-Ricerca aplicada. O item 2 é de autoria de Guido Sali, os itens 3, 4, 5 de Chiara Mazzocchi. A introdução e conclusões são de autoria de ambos. Artigo originalmente enviado em italiano. Traduzido por Valeria de Marcos (DG FFLCH USP - demarcos.vale@usp.br)
} 
Keywords: WTO, agricultural market, International agreements, geographical indications, club goods

\section{INTRODUÇÃO}

No pós-Segunda Guerra Mundial surgiram, e cresceram, os principais organismos internacionais, cujo objetivo era regulamentar as relações entre os Estados Nacionais, criando um contexto idôneo à convivência pacífica e ao estabelecimento de relações políticas, sociais e comerciais baseadas em um quadro de regras compartilhadas. Também a agricultura teve um papel fundamental no debate internacional sobre a regulamentação do mercado. Nos últimos anos foram solicitados esforços notáveis ao setor primário para a sua renovação voltados, por um lado, à modernização e à tecnologização do setor - em particular nos países em vias de desenvolvimento onde é ainda marcado o atraso do sistema agrícola no seu complexo. Por outro lado, as últimas Rodadas $^{2}$ internacionais desviaram a atenção dos Estados do tema nitidamente produtivista de uma agricultura dos "bens", para aquele mais abrangente de uma agricultura dos "serviços", entendidos especialmente como externalidades positivas, sobretudo nos países desenvolvidos. Paralelamente, a globalização do mercato tem colocado como central o tema da segurança alimentar, junto àquele da qualidade dos bens agroalimentares. Nesta ótica substancialmente diversa em relação às condições dos mercados globais, anteriormente afrontados pela agenda da Organização Mundial do Comércio, na Rodada do Uruguai foi colocada a discussão relativa às Indicações Geográficas graças à assinatura dos acordos TRIPs (ver item 3) sobre a Propriedade Intelectual. O presente artigo pretende apresentar uma reflexão sobre a funcionalidade das Indicações Geográficas como instrumento de mercado e sobre as suas potencialidades (itens $2,3,5$ ), apresentando um caso de estudo que mostra algumas criticidades evidentes (item 4) e traçando conclusões sintéticas (item 6).

\section{O ACORDO SOBRE A AGRICULTURA NA RODADA DO URUGUAI}

Entre os organismos que surgiram para melhorar as trocas comerciais, o GATT foi a sede de negociações onde ocorreram oito rodadas, de 1947 a 1984. As primeiras cinco rodadas assumiram a forma de negociações bilaterais paralelas, com o objetivo de

\footnotetext{
${ }^{2}$ Ver item sucessivo
} 
instaurar condições de reciprocidade mutuamente vantajosas. A sexta, concluída em 1967 e chamada de Rodada Kennedy, foi a primeira negociação multilateral, onde foi acordada uma queda generalizada das taxas alfandegárias de muitos produtos industriais (em média de 35\%). Também a sétima, a Rodada de Tóquio, concluída em 1979, teve ao centro das negociações a redução das taxas alfandegárias, além da instituição de novos instrumentos destinados a contrastar o surgimento e a expansão das barreiras alfandegárias.

$\mathrm{O}$ aspecto principal das primeiras sete rodadas do GATT consiste no fato de a agricultura e o comércio dos produtos agrícolas nunca terem sido incluídos na agenda das negociações. Foi necessário chegar à oitava negociação, a Rodada do Uruguai, para ocorrer o primeiro acordo multilateral sobre a agricultura - acordo que tanto tem influenciado na estrutura do setor agrícola nos países industrializados - e sobre a organização dos mercados agrícolas nos últimos 15 anos.

Deve-se lembrar, antes de mais nada, que as negociações sobre o comércio internacional têm o principal objetivo de estabelecer acordos que superem as tendências protecionistas e sejam, portanto, voltados a uma progressiva liberalização das trocas. Não é de se espantar, pois, o fato de que até os anos 1980 os atores mais influentes, Estados Unidos e Europa, não sentissem a necessidade de incentivar a realização de condições de troca mais abertas em relação àquelas vigentes. Se por um lado os Estados Unidos podiam conservar a sua independência na política agrícola, cuja origem se remete ao Agricultural Adjustment Act de 1933, por outro a então Comunidade Econômica Europeia estava empenhada desde 1960 na concretização da política agrícola comunitária (PAC), voltada a um forte protecionismo. Este era funcional ao incremento produtivo para a obtenção da autosuficiência alimentar, garantindo ao mesmo tempo renda adequada aos agricultores e preços convenientes aos consumidores. É possível, sem dúvida, atribuir à fase expansiva dos anos 1980 um papel significativo na determinação da necessidade de expansão dos mercados para o escoamento das produções dos países industrializados, necessidade que determina o aparecimento de diversas áreas de livre comércio em várias partes do mundo (Nafta, Mercosul). Esta situação envolveu também os produtos agrícolas, que justamente nos anos 1980 causaram a explosão da despesa comunitária para enfrentar os enormes excedentes produtivos, consequência eclatante de décadas de sustentação dos preços. Não apenas 
este último, mas também a gestão dos estoques e o subsídio às exportações contribuíram também para o elevado nível das despesas da PAC.

Nesta situação de crise da PAC a Rodada do Uruguai foi percebida pela União Europeia, e inclusive por outros países industrializados, também como ocasião para negociar a abertura dos próprios mercados agrícolas com aquele nos países em vias de desenvolvimento, a abertura de mercado dos produtos industriais e dos serviços, dos capitais e dos investimentos, de novos regimes de propriedade intelectual e também para os temas não estritamente comerciais.

O conjunto, pois, de vários fatores levou a maioria a considerar como conveniente a inclusão da agricultura nas negociações da Rodada do Uruguai, que se concluiu em 1994 com, entre outros, o Acordo sobre a Agricultura (AoA). Este acordo previa o empenho dos países signatários para que agissem em três frentes: redução do subsídio interno, dos subsídios às exportações e também das barreiras à importação. $\mathrm{O}$ acordo fixava um período de implantação entre 1995 e 2001. Entre os aspectos qualificantes devem ser destacados: o tratamento especial e diferenciado para os países em via de desenvolvimento; a cláusula de paz que prevê um período transitório (até o fim de 2003) em que não podem ser adotadas represálias por parte dos países danificados por políticas comerciais incorretas; a taxação das barreiras não tarifárias e o empenho em iniciar uma nova negociação até o ano 2000.

Como se sabe, entre os resultados da Rodada do Uruguay está o nascimento da Organização Mundial do Comércio (OMC) que constitui hoje, junto ao Fundo Monetário Internacional e ao Banco Mundial, um dos três pilares sobre os quais se sustenta a gestão da economia internacional. O salto organizativo é enorme porque, diversamente do GATT, a OMC é uma organização internacional a pleno título, e a adesão de um país a esta comporta direitos e deveres. Além disso, fornece os instrumentos para levar a termo as negociações comerciais e também para resolver as disputas, mediante a instituição das Dispute Settlement Body. Além de administrar os acordos, a OMC administra o monitoramento das políticas comerciais nacionais, fornece assistência aos países em vias de desenvolvimento e coopera com as outras instituições internacionais.

A ação da OMC é voltada à liberalização das trocas, e para conseguir tal objetivo se baseia em alguns princípios fundamentais que guiam a definição das regras e a solução das disputas. Entre estes, assumem particular importância o princípio de não discriminação, a regra do tratamento nacional, a proibição de restrições quantitativas à 
importação, a redução das barreiras tarifárias ou não, a redução das subvenções às exportações, e a flexibilidade na aplicação das regras para considerar as diversas realidades nacionais.

Voltando ao Acordo sobre a Agricultura, parece importante examinar as modalidades com as quais se afrontou o tema do subsídio interno, enquanto esta postura constitui a lente através da qual pode-se ler as variações de subsídio aos ganhos operados na União Europeia da reforma Mac Sharry, até hoje.

Com o AoA as inúmeras formas de subsídio ao setor agrícola presentes nos diversos países foram classificadas de acordo com o nível de distorção dos mercados que são capazes de determinar, chegando a definir as seguintes categorias de ajudas:

- ajudas não distorsivas, que podem ser distribuídas (catalogadas com o nome de green box). Fazem parte de tal tipologia o subsídio de tipo estrutural, os auxílios à pesquisa, as medidas de tutela ambiental, a formação, etc.;

- ajudas distorsivas, sujeitas a uma progressiva redução até a completa eliminação (amber box). Fazem parte desta tipologia todas as ajudas acopladas ao preço, e o valor total distribuído por um país constitui o seu Amber Distorting Support (AMS), sujeito a um teto de despesa;

- ajudas parcialmente distorsivas (blue box), mas consideradas não meritáveis de redução, pelo menos transitoriamente. Fazem parte os pagamentos diretos como aqueles introduzidos pela reforma Mac Sharry na União Europeia;

- ajudas de minimis, correspondentes a uma quantia de até 5\% do valor da produção agrícola de um país que pode ser gasta em subsídio sem que seja incluída no cálculo da AMS;

- subsídio interno distribuído em países em vias de desenvolvimento (Special and Differential Box).

Naturalmente as categorias acima descritas são muito diversas não apenas pelo tipo de ajuda concedida, mas também pela entidade e distribuição geográfica dos países em que são distribuídas (OECD, 2001).

Se consideramos os anos entre 1998 e 2002 notamos, antes de mais nada, que a nível mundial cerca de metade das ajudas são classificadas como green box, um terço como amber box e a quota restante subdividida entre blue box, quota de minimis e social and differential box. 
Também no âmbito de cada país os subsídios apresentam variações marcadas. Com relação ao valor da produção agrícola existem países que distribuem subsídios amplamente superiores à produção, como a Islândia (140\%) e Noruega (130\%), ou pouco inferiores, como a Suíça (85\%). Os grandes países industrializados como os Estados Unidos, a União Europeia e o Japão apresentam ajudas que correspondem a pouco menos de $40 \%$ da produção, enquanto todos os outros países distribuem ajudas decididamente mais modestas: se vai da Coreia e Israel em torno a $20 \%$, ao Brasil com cerca de $6 \%$, aos países em vias de desenvolvimento onde os subsídios são praticamente ausentes (Rae and Strutt, 2003).

No período em questão, o conjunto das ajudas distribuídas pela União Europeia era metade constituído por ajudas distorsivas (amber box), um quarto por blue box e um quarto por green box. Diversa era a situação nos Estados Unidos, onde quase três quartos das ajudas eram classificadas como não distorsivas (green box), e menos de um quarto como ajudas distorsivas. Mais ou menos análoga era a composição encontrada para o Japão. Deve-se observar, além disso, que $82 \%$ de todas as ajudas classificadas como amber box na Rodada do Uruguai são apanágio de apenas três países: União Europeia (59,8 bilhões de dólares), Japão $(35,9)$ e Estados Unidos $(19,1)$ (Blandford and Berkeley, 2005).

Um discurso à parte mérita a blue box, criada para classificar uma tipologia particular de ajudas que não são propriamente distorsivas mas indiretamente ligadas às quantidades produzidas e, portanto, capazes de incidir de modo indireto sobre as escolhas produtivas e de interferir parcialmente sobre os mecanismos de mercado. A blue box foi introduzida quase exclusivamente para considerar os pagamentos diretos concedidos na União Europeia após a reforma Mac Sharry e, de fato, em 1998 91,6\% do total das ajudas assim classificadas era distribuído na União Europeia (19,7 bilhões de dólares). Somente outros dois países usavam a blue box: a Noruega com 985 milhões de dólares $(4,6 \%)$ e o Japão com 831 milhões de dólares (3,9\%).

Tal situação foi modificando-se profundamente após o acordo de Genebra de 31 de julho de 2004, com o qual, desmentindo parcialmente as intenções expressas em sede de negociação, a OMC ampliou a tipologia das ajudas classificáveis como blue box (Blandford, 2005). Foram incluídos, de fato, também os pagamentos que não requerem produção agrícola, como por exemplo os pagamentos anticíclicos concedidos nos Estados Unidos aos produtores de algodão (World Trade Organization, 2004). Em virtude de tal decisão e em concomitância com o início da reforma Fischler na Europa a 
partir de 2005, a blue box parece hoje decididamente distinta: os Estados Unidos podem transferir quase 10 bilhões de dólares, enquanto a União Europeia reduziu a utilização, tendo transferido a quase totalidade dos seus próprios pagamentos para pagamento unico desemparelhado (green box).

\section{OS ACORDOS TRIPS E O REGISTRO INTERNACIONAL DOS VINHOS E DAS BEBIDAS ALCOÓLICAS}

Por ocasião do acordo conclusivo da Rodada do Uruguai em Marraquesh, em 1994, foram assinados os Trade Related Aspects of Intellectual Property Rights (TRIPs), ou seja, os acordos sobre a Propriedade Intelectual. No seio dos TRIPs figuravam também os produtos a Indicação Geográfica (IG) cujo reconhecimento foi aprovado por todos os países signatários, com os artigos 22, 23 e 24. Apesar destes acordos, hoje a regulamentação das IG ainda depende das leis nacionais e isto leva a uma limitação da eficácia. As grandes diferenças entre as legislações dos países membros da OMC sobre as IG dependem das suas história e cultura, mas podem seriamente ser influenciadas pelo grau de proteção jurídica fornecida pelos acordos TRIPs, débeis ou fortes (Arfini et al., 2010), das políticas predispostas através dos TRIPs (Mazzocchi, 2012). O artigo 22 confere uma proteção geral, extensiva a todos os produtos reconhecidos como Indicação Geográfica, mas é uma proteção negativa, ou seja, os países membros da OMC devem prover os meios legais para impedir o uso incorreto de uma indicação (ou proibição) por parte dos produtores não localizados na região designada por aquela própria indicação. Esta formulação jurídica representa uma tutela pouco eficaz. De fato, se alguém quisesse opor-se a um uso indevido de uma Indicação Geográfica, deveria provar que o uso do qual faz a contraparte é capaz de induzir o público a erro. Uma proteção mais específica é garantida pelo art. 23 dedicado exclusivamente aos vinhos e bebidas alcoólicas $^{3}$. Isto comporta, por exemplo, que em respeito ao artigo 23 não é possível usar indicações como "vinho frizante tipo Champagne, produzido no Chile" ou "Tequila Suíça”, enquanto segundo o artigo 22 é possível escrever "Queijo Roquefort, produzido na Noruega", ou "Tapete Bukhara, made in USA".

De fato, os últimos casos mencionados poderiam ser considerados por um juiz como não enganosos para o público, a partir do momento em que vem indicada a verdadeira

\footnotetext{
${ }^{3}$ Vinhos e Bebidas Alcoólicas.
} 
origem do produto (Arfini et al, 2010). O mais alto nível de proteção é garantido aos vinhos particulares (seção 4, art. 23). Além disso, o art. 23 preve a predisposição de um registro internacional dos vinhos a Indicação Geográfica que lhes conferiria um status específico, com pleno valor jurídico em todos os países membros. A implementação de tal registro foi debatida por muito tempo mas isto nunca foi predisposto, apesar da Declaração de Doha em 2001 ter vivamente sugerido a realização. Os TRIPs, portanto, deram o mandato para a criação do registro com negociações que iniciaram em 1994, e atualmente existem três propostas em discussão que refletem as posições dos vários Estados membros:

- Joint Proposal Group - Criação de um banco de dados de IG registradas, que tenha força sob a legislação nacional e seja voluntário. Fazem parte do grupo: Argentina, Austrália, Canadá, Chile, Costa Rica, República Dominicana, Equador, El Salvador, Guatemala, Honduras, Israel, Japão, Coreia, México, Nova Zelândia, Nicarágua, Paraguai, África do Sul, Taiwan, Estados Unidos ${ }^{4}$.

- Modalities Group - Criação de um registro no qual é obrigatória aos membros a inscrição de suas IG, que teria efeito em todos os Estados membros ${ }^{5}$. Os Estados compreendidos no Modalities Group são: Albânia, Brasil, China, Colômbia, Croácia, Equador, União Europeia, Georgia, Islanda, Índia, Indonésia, Quirguistão, Liechtenstein, Moldávia, Macedônia, Paquistão, Peru, Srilanca, Suíça, Tailandia, Turquia, ACP Grupo e o Grupo Africano.

- Posição “intermediária" proposta por Hong Kong ${ }^{6}$ que prevê alguns pressupostos obrigatórios e a participação voluntária dos Membros.

No mês de abril de 2011, os grupos de negociação da Rodada de Doha difundiram um Draft Text (Dallington, 2011) que unia pela primeira vez em um único texto as propostas e as posições dos membros durante as negociações do último ano, que porém está bem longe de representar um acordo entre os diversos pontos de vista (MeierEwert, 2011).

\footnotetext{
${ }^{4}$ Abril de 2011.

5 Julho de 2008.

${ }^{6}$ Abril de 2003.
} 


\section{NOMES GEOGRÁFICOS E NOMES GENÉRICOS: O CASO DO FETA}

A dificuldade na criação de um registro com valor jurídico para os vinhos, e potencialmente para qualquer outro produto a marca de origem geográfica, impõe uma reflexão sobre a importância efetiva destes instrumentos e sobre os interesses em jogo. De um lado, estão os Países que desde sempre defendem a tipicidade e a unicidade das suas produções alimentares, estreitamente ligados à economia agrícola dos próprios Estados, e que reivindicam a necessidade e também o direito de proteger legalmente, e de maneira compartilhada no mercado internacional, a marca de origem dos próprios produtos, como garantia de qualidade. De outro lado estão aqueles Países que, ou por razões de pouco interesse por estes tipos de produções, ou por razões de interesse a um mercado agrícola totalmente liberalizado, portanto sem vínculos legislativos nem ajudas monetárias, não aprovam uma política de proteção da origem geográfica dos produtos. Uma das razões do desinteresse, aliás, da oposição a estes tipos de instrumentos legislativos é o fato de que geralmente se tratam de países fortemente exportadores de matérias-primas agrícolas ou produtos alimentares, favoráveis portanto a um mercado com menos barreiras possíveis. Some-se a isso que alguns destes Países ${ }^{7}$ são economias em vias de desenvolvimento, e portanto sofrem as consequências das políticas de subsídios que os países desenvolvidos concedem aos seus agricultores, e nos instrumentos de proteção da origem dos produtos apenas vêem barreiras que se seguirão aos próprios investimentos e exportações. Por outro lado, entram em jogo interesses geopolíticos de alianças econômicas entre Estados, que colocam em segundo plano aqueles que deveriam ser os objetivos da implantação de instrumentos de proteção jurídica dos produtos a Indicação Geográfica. De fato, a defesa da tipicidade das produções deveria ter a função de proteger a agricultura dos efeitos negativos da globalização dos mercados, através da proteção do ambiente, da história, da cultura, dos processos produtivos tradicionais que representam e sustentam as economias dos lugares em que nasceram. Devido a distorções do mercado, a questão das Indicações Geográficas tranformou-se no paradoxo de si própria: não mais instrumento para proteger e incentivar a economia dos territórios de onde provêm o produto, mas impedimento ao livre comércio e ao desenvolvimento dos Países. A principal qualidade

\footnotetext{
${ }^{7}$ Se tratam dos países que fazem parte do Joint Proposal Group, alguns dos quais, como Argentina, Chile, Equador, mas também África do Sul, são economias em vias de desenvolvimento com forte propensão à exportação de produtos agrícolas.
} 
da marca geográfica deveria consistir na unicidade da proposta do produto, irreproduzível em outro local com as mesmas características. Na realidade, as Indicações Geográficas não são exatamente definíveis como marcas mas sim como "sinais distintivos", pois os seus usos são justamente exclusivos daqueles que se encontram em uma zona geográfica delimitada. De fato, um dos piores danos relativos aos produtos à Indicação Geográfica - porque irreparável - é a perda da unicidade do nome geográfico, ou seja, a perda do significado do próprio nome, que de especifico se torna genérico. A pouca proteção fornecida aos "nomes geográficos" incentiva o risco de que se transformem em nomes genéricos e possam por isso ser usados livremente no tempo por qualquer um, tornando-se o nome de uma inteira categoria de produtos. Uma transformação similar pressupõe que um nome geográfico tenha sido utilizado como nome comum por décadas e sobre uma ampla porção de território, e que o produto assim designado não possa mais ser associado ao lugar ao qual deve sua fama.

Além disso, a transformação deve ser completa e o retrocesso, impossível. Emblemático é o caso do Feta, um queijo de origem grega que o Estado helênico propôs registrar como Denominação de Origem Protegida em 1994, o que, porém, encontrou inúmeros obstáculos devido à suposta generalidade do nome antes do registro propriamente dito. De fato à proposta apresentada pela Grécia o comitê científico disposto pela Comissão Européia deu parecer positivo considerando o nome "Feta" não genérico e, portanto, registrável como "geográfico". Mas dois anos depois, segundo o procedimento europeu, a Comissão Européia solicitou ao Comitê de Regulamentação das Denominações de Origem Protegidas (DOP) e das Indicações Geográficas Protegidas (IGP) a emissão de um parecer sobre o projeto de regulamento englobando também o "Feta" como DOP.

O resultado foi o seguinte: 45 votos favoráveis (Bélgica, Grécia, Espanha, Itália, Luxemburgo, França e Portugal) e 42 votos contrários (Dinamarca, Alemanha, Irlanda, Países Baixos, Reino Unido, Suécia, Finlândia e Áustria). A Dinamarca, a Alemanha, a Irlanda, os Países Baixos, o Reino Unido, a Áustria, a Finlândia e a Suécia fizeram observar que a proposta continha denominações de produtos, como 'Feta', que nos seus entendimentos eram genéricos (COM, 2002).

$\mathrm{Na}$ falta de um parecer do Comitê, a Comissão Europeia transmitiu as propostas de medidas ao Conselho de Ministros da Agricultura de 20 de maio de 1996, onde a Dinamarca, a Alemanha, a França, a Irlanda, a Áustria, a Finlândia e a Suécia se opuseram às medidas propostas, o Reino Unido se absteve, enquanto a Grécia, Espanha, Portugal, Itália, Luxemburgo, Bélgica e os Países Baixos concederam o acordo. Devido 
a ausência de parecer por parte do Conselho, a Comissão adotou, segundo o procedimento do Comitê de Regulamentação, o regulamento proposto: (CE) n. 1107/96. A este ponto Alemanha, Dinamarca e França entraram com recurso para a anulação parcial do regulamento apenas aprovado. As razões dos três Estados foram que: a) a área geográfica interessada pela produção do Feta se extendia por todo o território grego, uma inteira nação, o que é excluído pelo regulamento para as denominações tradicionais não geográficas ${ }^{8}$, e b) "Feta" vinha considerado como um nome genérico, portanto não específico. Vale a pena destacar que os três Estados eram também os maiores produtores deste queijo, depois da Grécia, no mercado europeu.

A Corte de Justiça da Comunidade Europeia decidiu, com uma sentença de 16/3/99, que a Comissão não tinha levado em consideração todos os fatores previstos pelo Reg. 2081/92 e decidiu pela anulação parcial do Reg. 1107/96. A Comissão pediu aos Estados membros o fornecimento de dados completos sobre produção, consumo e conhecimento efetivo da denominação "Feta" por parte dos consumidores europeus. O Comitê Científico, examinados os dados fornecidos pelos Países, decidiu que o termo "Feta" não podia ser considerado genérico e, portanto, podia ser registrado entre as Indicações Geográficas.

Em particular as razões pelas quais o "Feta" não podia ser considerado um nome genérico foram:

1) a produção e o consumo do «Feta» eram concentrados na Grécia;

2) os produtos comercializados como "Feta" pelos outros Estados membros eram na maior parte de leite de vaca, produzidos com tecnologia diferente e destinados a países terceiros, fora da União Europeia, por isso "não se pode, portanto, afirmar que a denominação «Feta» possua carater genérico, enquanto que no mercado único predomina o produto grego original" (COM, 2002);

3) o nome «Feta» evoca sempre a origem grega e portanto não se trata de um nome que se tornou comum, e portanto genérico, no território comunitário.

$\mathrm{O}$ caso do Feta apresenta as contradições dos instrumentos legislativos que regulamentam as Indicações Geográficas e em particular a questão do livre comércio entre os países.

\footnotetext{
${ }^{8}$ Segundo o Reg.2081/92.
} 


\section{A ESCOLHA DAS INDICAÇÕES GEOGRÁFICAS}

A avaliação do impacto econômico das Indicações Geográficas deve considerar inúmeros fatores, entre eles a consciência da escolha por parte dos produtores ao aderir ao disciplinar específico, e por parte dos consumidores de adquirir o produto com denominação por suas próprias características. Do lado da oferta, o instrumento das Indicações Geográficas se enquadra nos assim chamados "bens de clube". Os bens econômicos se diferenciam em bens de caráter público ou privado, ou ainda misto. A classificação dos bens se baseia em princípios de não excludibilidade e não rivalidade: um bem é definido não excluível se todos podem dele desfrutar indistintamente e ninguém pode ser excluído; é definido não rival quando cada sujeito pode desfrutá-lo sem comprometer o desfrute por parte de outros sujeitos. Existem também os bens "impuros", ou seja, que possuem caráteres mistos de um e de outro grupo de bens. Os bens de clube enquandram-se nesta terceira categoria e incluem aqueles bens que têm características de não rivalidade mas de excludibilidade; são definidos bens coletivos (Tiebout, 1956; Oison, 1965) consumidos por uma comunidade limitada de sujeitos. De acordo com Torré (2002:42) também os bens com Indicação Geográfica podem ser considerados bens de clube, normalmente descritos pelas seguintes características:

1) a fruição dos bens de clube é uma escolha voluntária, contrariamente àquela dos bens públicos que pode ser totalmente passiva, que se funda na convicção de que a utilidade obtida pelo membro do clube é mais alta do que aquela de um não membro;

2) os bens de clube podem ir ao encontro de fenômenos de congestão, devidos à superutilização do bem por parte do clube, por exemplo pelo número excessivo de membros;

3) os bens de clube são consumidos por um grupo exclusivo de indivíduos de número limitado, fundado sobre um mecanismo de exclusão de entrada, graças a parâmetros próprios de cada clube.

Os produtos com a denominação de origem geográfica compreendem produtores que se enquadram na zona delimitada pelo produto com marca, sob pena de exclusão da possibilidade de produzir; uma outra característica necessária é a adesão dos produtores ao disciplinar que estabelece as regras da própria produção: estas características descrevem as Indicações Geográficas como bens de clube. A peculiaridade do instrumento das IG deriva também das características dos bens de clube. De fato, a exclusividade do grupo de produtores limitado a uma área geográfica define, 
consequentemente, também a dimensão física do mercado da oferta: se de fato potencialmenteela esta puder ser infinita, com a definição de uma área geográfica, sobretudo nos casos em que resulte de pequena extensão, se torna limitada. Neste sentido as Indicações Geográficas podem ser definidas como um instrumento de mercado de caráter protecionista, pois são pela sua natureza, além do que pela definição legislativa, produtos exclusivos de uma determinada área. Este é um dos elementos do debate internacional que não consentiu às Indicações Geográficas tornarem-se um instrumento compartilhado e aceito, mas sobretudo utilizado, por todos os Países, e é uma das motivações que alicerçam a disputa relativa à implementação do "Registro dos vinhos e das bebidas alcoólicas", como tratado no item 3. Ainda assim a denominação de origem geográfica no âmbito das características da demanda de bens agroalimentares, confere ao produto características de tipicidade que o tornam único, e portanto, em alguns casos, insubstituível na lista dos bens adquiríveis pelos consumidores. Por exemplo, sobre a base da teoria das experiências (Pine et al., 2000) os bens e os serviços podem ser divididos em quatro categorias (Pencarelli et al., 2006:4):

- As matérias-primas são materiais substituíveis extraidos do mundo natural;

- Os bens são manufaturados, portanto, produtos do trabalho humano, padronizados e armazenáveis;

- Os serviços são atividades que respondem às solicitações da demanda e que têm características de intangibilidade. Aqueles que oferecem um serviço utilizam os bens (tangíveis) para obter os seus produtos e satisfazer as solicitações dos clientes; os serviços têm a função de satisfazer exigências dos clientes que "querem ver satisfeitos";

- As experiências são eventos memoráveis que envolvem os indivíduos no plano pessoal, e se diferenciam dos serviços porque miram envolver o cliente na satisfação de uma sua necessidade, mais ou menos percebida, em um evento que visa enriquecer o sujeito que o vive;

- As transformações são mudanças individuais produzidas nas pessoas; nelas o consumidor escolhe viver um "acontecimento" ou um processo que modifique em algum modo as suas características; um exemplo de transformação é a de frequentar um curso de body building ou de inscrever-se a uma business school.

Nesta perspectiva os produtos com denominação são enquadráveis, de acordo com a tipologia de oferta, também na categoria das experiências e/ou transformações, 
revelando-se um instrumento particularmente interessante do ponto de vista do marketing e do desenvolvimento territorial. Baseados nestas considerações eles são interessantes não apenas do ponto de vista produtivo, como elemento de desenvolvimento de um mercado "de nicho", mas também do ponto de vista do estímulo das economias locais: se tornam, por isso, um instrumento útil para todos os Países a nível internacional.

Ao contrário, do lado da demanda, uma criticidade a ser considerada comum a todos os bens inseridos no mercado é aquela das assimetrias informativas (Akerlof, 1970) que não permite aos consumidores operar uma escolha de compra totalmente consciente. Isto é dado pelo fato de que os consumidores frequentemente não dispõem de todos os elementos necessários para ter completo controle sobre os próprios consumos, no sentido de que não possuem informações suficientes para efetuá-los com racionalidade, devido ao escasso conhecimento sobre os próprios produtos. Esta assimetria é mais marcada para os produtos que possuem pouca difusão no mercado por questões de baixa produção por exemplo, e geralmente para aqueles produtos que não dispõem de um sistema de divulgação suficientemente eficiente. Em particular, os produtos de denominação com uma produção não elevada e que são produzidos em áreas geográficas muito limitadas, frequentemente não têm um suporte midiático tal de poder consentir a difusão e a divulgação das próprias características a uma massa adequada de consumidores. A tutela e o enquadramento internacional dos produtos com denominação de origem são, portanto, absolutamente necessários para consentir um adequado desenvolvimento em todo o mundo.

\section{CONCLUSÕES}

É possível, pois, concluir que o sistema de regras originadas do acordo sobre a agricultura na Rodada do Uruguai está ainda bem longe de garantir tanto um sistema de livre comércio - considerando a possibilidade, para os Países que possuem recursos, de provocar evidentes distorções de mercado através do subsídio interno -, como um adequado nível de proteção das produções típicas locais. Neste contexto, portanto, os países de baixa renda, que notoriamente não possuem significativos recursos públicos para o subsídio interno - e em particular daqueles agrícolas - sofrem níveis de concorrência não raro insustentáveis. 
De fato, em uma economia globalizada onde a liberalização do mercado é propagandada como a melhor solução para o desenvolvimento econômico dos Países, o sistema das Indicações Geográficas é objetivamente uma restrição de tipo protecionista. Mas se se consideram as diferenças entre os Países e entre as instituições econômicas e políticas existentes, é possível afirmar que as intervenções de valorização e proteção jurídica dos produtos a Indicação Geográfica, se utilizados corretamente, podem se tornar um instrumento útil a todos os Países, e não apenas a alguns, para tutelar a especificidade dos próprios territórios, das próprias tradições e da própria cultura.

De qualquer modo, deve sempre ser recordada uma reflexão de John K. Galbraith para quem

a verdade é que nenhum país industrial - nem os Estados Unidos, nem o Canadá, nem os países da União Europeia, nem os outros países europeus, como bem sabemos o Japão - deixam os seus agricultores à revelia do livre mercado. Nenhum. Aqueles que defendem os benefícios do livre mercado na agricultura falam de algo que não existe na realidade. (Galbraith, 1987)

\section{BIBLIOGRAFIA}

ARFINI F., Belletti G., Marescotti A, Prodotti tipici e denominazioni geografiche, strumenti di tutela e valorizzazione, Roma: Tellus, 2010.

BLANDFORD D., Disciplines on Domestic Support in the Doha Round, Trade Policy Issues Paper n.1, International Agricultural Trade Research Consortium, 2005.

BLANDFORD D., Berkeley H., Facilitating farm-level adjustment to the Reform of trade and agricultural policies, Trade Policy Issues Paper n.4, International Agricultural Trade Research Consortium, 2005.

COM, Proposta di regolamento del Consiglio che modifica l'allegato del regolamento (CE) n. 1107/96 della Commissione per quanto riguarda la denominazione «Feta»/* COM/2002/0314 def., Gazzetta ufficiale n. 262 E del 29/10/2002 pp. $0284-0291.2002$

DALLINGTON M., Multilateral system of notification and registration of geographical indications for wines and spirits, Report of the special session of Council of Trade related Aspects of Intellectual Property Rights, 21 april 2011. Disponível em: http://www.wto.org/english/tratop_e/trips_e/ta docs_e/5 1 tnip21_e.pdf Acesso em: $22 / 04 / 13$

GALBRAITH J.K., Agricultural Policy: Ideology, Theology and Reality Over the Years, National Governors' Conference, Traverse City, Michigan, 27 July 1987. 
JOSLING, T., New Farm Programs in North America and Their Treatment in the WTO: Discussion, American Journal of Agricultural Economics v. 82, p. 775-777, 2000.

MAZZOCCHI C., Sali G., Classification of Geographical Indications: a proposal of codification, Journal of Intellectual Property Rights, v. 17, 218-225, 2012.

MEIER-EWERT W., Geographical Indications in the WTO, news from the Doha round of negotiations. In: WIPO WORLDWIDE SYMPOSIUM ON GEOGRAPHICAL INDICATION, 2011, Lima. Anais eletrônicos... Lima, 2011. Disponível em: http://www.wipo.int/meetings/en/doc_details.jsp?doc_id=171861. Acesso em: $22 / 04 / 13$

OECD, The Uruguay Round Agreement on Agriculture: An Evaluation of its Implementation in OECD Countries, Paris: OECD, 2001.

OLSON M., The logic of collective action. Cambridge:Harvard University Press, 1965.

PENCARELLI T., Forlani F., Il marketing dei prodotti tipici nella prospettiva dell'economia delle esperienze. In: CONGRESSO INTERNAZIONALE "LE TENDENZE DEL MARKETING", 2006, Venezia. Venezia: Università Ca' Foscari Venezia, p.1-20, 2006. Disponível em: http://www.econ.uniurb.it/materiale/2538 marketing\%20prodotti\%20tipici.pdf. Acesso em: 22/04/13

RAE A.N., Strutt A., Doha Proposals For Domestic Support: Assessing The Priorities, Working paper, 2003.

THÉVENOD-MOTTET E., GI Legal and Istitutional Issues, SINER-GI project report WP1. 2006. Disponível em: http://www.origin-food.org. Acesso em: 22/04/13

TIEBOUT C., A pure theory of local expenditure, Journal of Political Economy, v. 64, p. 416-24, 1956.

TORRE A. (2002), Les AOC sont-elles des clubs ? Réflexions sur les conditions de l'action collective localisée, entre coopération et règles formelles, Revue d'économie industrielle, Vol. 100, p. 39-62. Disponível em: http://www.persee.fr/web/revues/home/prescript/article/rei_015432292002 num 100_1_984. Acesso em: 22/04/13

WORLD TRADE ORGANIZATION, United States - Subsidies on Upland Cotton, WT/DS267/R. September 8. Geneva, 2004. 